\title{
Spor Bilimleri Öğrencilerinin Uzaktan Eğitime Yönelik Tutum ve Görüşlerinin İncelenmesi
}

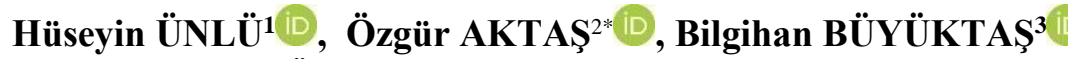 \\ ${ }^{1}$ Aksaray Üniversitesi, Spor Bilimleri Fakültesi, Aksaray. \\ ${ }^{2}$ Kilis 7 Aralık Üniversitesi, Beden Eğitimi ve Spor Yüksekokulu, Kilis. \\ ${ }^{3}$ Çukurova Üniversitesi, Spor Bilimleri Fakültesi, Adana.
}

Orijinal Makale

Gönderi Tarihi: 02.07.2021
Kabul Tarihi:21.11.2021
DOI: $10.25307 /$ jssr.961588

Online Yayın Tarihi: 31.12.2021

\section{Öz}

COVID-19 pandemisi sebebiyle eğitim öğretim faaliyetlerinin uzaktan yürütülmesi kararı alınmış ve aniden uzaktan eğitime geçen öğrencilerin derslerine yönelik tutumları, görüşleri merak konusu olmuştur. $\mathrm{Bu}$ araştırma spor bilimleri alanında yükseköğrenim gören öğrencilerin koronavirüs (COVID-19) pandemisinden dolayı uzaktan eğitim yöntemiyle işlenen derslere karşı görüşlerini ve tutumlarını ortaya çıkarmak amacıyla yapılmıştır. Yaş ortalamaları 21,78 $\pm 3,17$ olan 106 kız, 150 erkek toplam 256 üniversite öğrencisi araştırmaya katılmıştır. Araştırmada öğrencilerin uzaktan eğitime yönelik tutumlarını belirlemek amacıyla 'Uzaktan Eğitime Karşı Tutum Ölçeği' kullanılmıştır. Araştırmada ikili grup karşılaştırmaları için bağımsız örneklem t testi, ikiden fazla grup karşılaştırmaları için tek yönlü varyans analizi (one-way Anova) testi kullanılmış, anlamlılık düzeyi <.05 olarak kabul edilmiştir. Ayrıca, öğrencilerin uzaktan eğitime yönelik görüşlerini ortaya çıkarmak adına araştırmacılar tarafından hazırlanan iki yarı yapılandırılmış soru ögrenciler tarafından cevaplanmış ve sorular içerik analizi yöntemiyle incelenmiştir. Cinsiyet ve bölüm değişkenlerinin uzaktan eğitime yönelik tutum üzerinde anlamlı bir farklılı̆ga sebep olmadığı saptanmıştır. Öğrencilere göre uzaktan eğitimin avantajlı yönleri; pandemiden kaynaklı yüz yüze eğitimin taşıdığı risk, zaman ve mekân avantajı sunması ve eğitimde firsat eşitliği sunması olmak üzere üç alt tema, dezavantajlı buldukları yönleri ise; yüz yüze eğitimin getirdiği avantajları ortadan kaldırması ve fizikî şartların yeterli olmaması faktörleri olmak üzere iki alt tema altında toplanmıștır. Sonuç olarak spor bilimleri öğrencileri mevcut pandemiden dolayı uzaktan eğitimin avantajlı olduğunu belirtseler de dezavantajlı yönlerinin de eğitim faaliyetleri için ciddi sorun teşkil ettiğini vurguladılar.

Anahtar kelimeler: COVID-19, Spor bilimleri, Tutum, Uzaktan eğitim.

\section{Investigation of Sports Science Students 'Attitudes and Opinions towards Distance Education}

\begin{abstract}
Due to the COVID-19 pandemic, it was decided to conduct education activities distance and the attitudes and views of students who suddenly switched to distance education have been a matter of curiosity. This research was conducted in order to reveal the opinions and attitudes of the students studying in the field of sports sciences towards the courses taught by the distance education method due to the coronavirus (COVID-19) pandemic. A total of 256 university students, 106 girls and 150 boys, with a mean age of $21.78 \pm 13.17$, participated in the study. In the study, "Attitude Scale towards Distance Education" was used to determine students' attitudes towards distance education. In the study, independent sample t test was used for paired group comparisons and one-way analysis of variance (Anova) test was used for comparisons of more than two groups, and the level of significance was accepted as <.05. In addition, two semi-structured questions prepared by the researchers in order to reveal the students' views on distance education were answered by the students and examined using content analysis method. It was determined that gender and department variables do not cause a significant difference on attitude towards distance education. Advantages of distance education according to students; The risk of face-to-face education arising from the pandemic is three sub-themes, which are the advantage of time and place, and the equality of opportunity in education. The aspects they find disadvantageous are; It has been grouped under two sub-themes: eliminating the advantages of face-to-face education and insufficient physical conditions. As a result, although the sport sciences students' stated that distance education is advantageous due to the current pandemic, they emphasized that its disadvantages also pose a serious problem for educational activities.
\end{abstract}

Keywords: COVID-19, Sport sciences, Attitude, Distance education.

\footnotetext{
"Sorumlu Yazar: Özgür AKTAŞ, E-mail: ozgur.72372@gmail.com
} 


\section{GíRiş}

Eğitim öğretim faaliyetlerine sınırlamalar getirdiği varsayılan zaman ve mekân kavramlarının doğrudan etkisinin olmadığı biçimlendirilmiş eğitim şekline uzaktan eğitim denir (King ve vd., 2001). Ayrıca e-öğrenme ve çevrim içi öğrenme olarak da ifade edilen uzaktan eğitim kavramı, eğitim öğretim faaliyetleri sürdürülürken öğretmen ve öğrencilerin aynı ortamda fiziki olarak bulunmamasını (Kaplan ve Haenlein, 2016) ve bireylerin iletişimini kolaylaştırmak adına farklı teknolojilerin kullanılmasını kapsayan eğitim biçimi olarak da karşımıza çıkmaktadır (Sutiah, Slamet, Shafqat ve Supriyono, 2020). Uzaktan eğitimin yaşam boyu öğrenme (Alharthi, 2020; Pambayun, Wirjawan, Wijaya, Untung ve Pratidhina, 2019; Serhan, 2019) sunmasına ek olarak eğitim maliyetlerini azaltması (Al-Husban, 2020; Baggaley, 2008; Hall ve Knox, 2009; Harrison ve Lee, 2018) eğitimin sürdürülebilirliğini sağlaması (Akinbadewa ve Sofowora, 2020; Bruder, 1989; Omiles, Dumlao, Rubio ve Ramirez, 2019; Seage ve Türegün, 2020) gibi faydaları bulunmaktadır. Ayrıca araştırmacılar uzaktan eğitimin teknik imkanlarına değinirken aynı zamanda pratik deneyimin çok az olması, öğrenci ve ebeveynlerin psikolojik hazırllğı̆ın olmaması gibi birtakım sorunlara da dikkat çekmektedirler (Yakovleva ve Koriakina, 2020). Nitekim birçok üniversitenin fayda sağlayacak çevrim içi öğretim için yeterli altyapısı veya kaynağının olmayışı (Dill, Fischer, McMurtrie ve Supiano, 2020), evde dizüstü bilgisayara ve internet olanaklarına erişimi olmayan öğrencilerin olması, ders içeriğinde uygulama ve deney olan derslerin işlenişinin uzaktan zor olması (Sahu, 2020) gibi konulara ek olarak çevrim içi eğitimin kalitesi de uygun şekilde tartışılması gereken kritik bir konudur (Goad, Towner, Jones ve Bulger, 2019; Sahu, 2020).

Dünyadaki birçok kurumsal organizasyon için popüler ve alternatif öğretim yöntemi olarak uzaktan eğitim sistemi kullanılmaktadır (Sawang, Newton ve Jamieson, 2013). Hatta mevcut yüz yüze sınıfların çevrim içi sınıflara dönüştürülmesi düşüncesi eğitim alanında tartışılan oldukça eski ve kalııı bir konudur (Yu ve Jee, 2021). Nitekim alan yazında beden eğitimi ve spor bilimleri faaliyetlerinin uzaktan yürütülmesiyle ilgili deneyimlerin paylaşıldığı yurtdışı kaynaklı araştırmalar (Beard ve Konukman, 2020; Chen, 2014; Daum, 2020; Frimming ve Bordelon, 2016; Goad ve diğerleri, 2019; Mohnsen, 2012; Pierre, 1998) bulunmaktadır. Ayrıca uzaktan eğitim konusu, pandemi sebebiyle yurt içindeki beden eğitimi ve spor bilimleri alanında çalışmalar yapan araştırmacıların da (Aktaş, Büyüktaş, Gülle ve Yıldız, 2020; Aras ve Karakaya, 2020; Ekiz, 2020; Özcan ve Saraç, 2020) dikkatini çekmiş ve konuyla ilgili bilimsel araştırmalar yayımlanmıştır. Yerli ve yabancı literatür genel olarak; uzaktan eğitimde karşılaşılan problemleri tespit edip alternatif çözüm önerileri sunma, teknolojik gelişmelerin spor bilimlerine uyarlanması ve uzaktan etkili bir öğrenme ortamı oluşturma hususunda spor bilimleri alanındaki bilgi birikiminin artışına katkı sağlamıştır.

Türkiye'de uzaktan eğitim ile ilgili oldukça geniş kapsamlı araştırmalar yapılmışıtr. Nitekim üniversite öğrencilerinin uzaktan eğitime yönelik görüşlerini (Akgün, 2020; Altuntaş, Başaran, Özeke ve Yılmaz, 2020; Bingöl, 2020a; Buluk ve Eşitti, 2020; Genç, Zengin ve Yardım, 2020; Gürler, Uslu ve Daştan, 2020; Orçanlı ve Bekmezci, 2020; Saltürk ve Güngör, 2020) ve uzaktan eğitime yönelik tutumlarını (Aktaş ve diğerleri, 2020; Yakar ve Yakar, 2021) inceleyen araştırmalar mevcuttur. Eğitim öğretim faaliyetlerinin diğer bir paydaşı olan öğretim elemanlarını da konu edinen (Bingöl, 2020b; Sayan, 2020; Şen ve Kızılcalığlu, 2020) araştırmalar alan yazına kazandırılmıştır. 
COVID-19 pandemisi küresel anlamda yaşamın her alanını olumsuz olarak etkilese dahi eğitim faaliyetleri bir kenara bırakılmamıştır. UNESCO'ya göre, 20 Nisan 2020'de eğitim kurumlarının kapatılması dünyadaki öğrencilerin \%91,3'ünün (1.575.270.054) bu eğitim durumunu etkilemiş olup sayı üniversite öğrencilerini de kapsamaktadır (UNESCO, 2020). $\mathrm{Bu}$ bilgiden hareketle Türkiye dışındaki ülkelerde de üniversitelerde uygulanan uzaktan eğitimle ilgili geniş kapsamlı (Agasisti ve Soncin; 2020, Assaf, 2020; Blankenberger ve Williams, 2020; Byrnes, Civantos, Go, McWilliams ve Rajasekaran, 2020; de Boer, 2020; Naidoo ve Cartwright, 2020; Suleri, 2020; Tiwari, Séraphin ve Chowdhary, 2020) araştırmalar yapılmıştır.

COVID-19 pandemisi nedeniyle tüm öğretim kademelerinde derslerin uzaktan eğitim yoluyla verilmesi bir zorunluluk olmuştur. Özellikle uygulamaya ve beceri eğitimine yönelik oldukça fazla içeriğe sahip olan spor bilimleri fakültelerinde okutulan derslerin uzaktan eğitim yoluyla verilmesi Türkiye'de var olan bir durum değildi. Bu süreçte spor bilimleri fakültesinde öğrenim gören öğrencilerin uzaktan eğitime yönelik tutumları ve görüşleri derslerden elde edecekleri kazanımları da etkileyecektir. Bu sebepten dolayı bu araştırmada spor bilimleri fakültelerinde öğrenim gören öğrencilerin uzaktan eğitime yönelik tutumları ve görüşleri incelenmiştir.

\section{YÖNTEM}

\section{Araştırma Modeli}

$\mathrm{Bu}$ araştırma spor bilimleri fakültelerinde öğrenim gören öğrencilerin uzaktan eğitime yönelik tutumlarını ve görüşlerini belirlemek amacıyla karma yöntemle tasarlanmıştır. Karma yöntem, araştırmacının problemi anlamak için nicel ve nitel verileri toplayan iki veri setini birbirine entegre ettiği ve ardından bu iki seti birbirine entegre etmenin avantajlarını kullanıp sonuçlara ulaştığı bir modeldir. Bu model genel olarak sağlık alanı, sosyal alan ve davranış bilimleri alanlarında tercih edilmektedir (Creswell, 2017). Araştırmada karma yöntem modellerinden paralel yöntem kullanılmıştır. Paralel yöntem araştırmalarında amaç eş zamanlı olarak hem nitel hem de nicel verileri toplamak, bu verileri birleştirmek ve bir araştırma problemini anlamak için çıkan sonuçları kullanmaktır (Fırat, Yurdakul ve Ersoy, 2014).

\section{Araştırma Grubu}

$\mathrm{Bu}$ araştırmada örnekleme yöntemlerinden olan kolay erişilebilir (gelişigüzel) örnekleme tercih edilmiştir. Gelişigüzel örneklem seçiminde detaylı bir çalışma yapılmaz. Bundan dolayı planlı olarak bir örneklem belirleme süreci de olmaz. Çoğunlukla örneklemin büyüklügü araştırmacının tercihine bağlıdır (Baştürk ve Taştepe, 2013). Bu kapsamda bu araştırmanın, araştırma grubunu 2019-2020 Eğitim-Öğretim Yılı Bahar Dönemi içerisinde farklı üniversitelerin spor bilimleri alanında eğitim gören 106'sı kadın $(\% 41,5)$ ve 150'si erkek $(\% 58,5)$ olmak üzere toplam 256 üniversite öğrencisi oluşturmuştur. Bu öğrencilerin yaş ortalamaları 21,78 $\pm 3,17$ olup 99'u beden eğitimi ve spor öğretmenliği, 83'ü antrenörlük eğitimi, 74 ise spor yöneticiliği bölümlerinde öğrenim görmektedir.

\section{Araştırma Yayın Etiği}

Aksaray Üniversitesi Etik Kurulu'nun 2020/06-90 sayı ve 22/06/2020 tarihli karar1 ile mevcut araştırmanın etik kurallara uygun olduğuna dair onay alınmıştır. 


\section{Veri Toplama Araçları}

Kişisel Bilgi Formu: Spor bilimleri alanında öğrenim görenlerin cinsiyet ve öğrenim gördükleri bölüm gibi demografik özelliklerini saptamak için araştırmacılar tarafından oluşturulmuştur.

Uzaktan Eğitime Yönelik Tutum Ölçeği: Ağır (2008) tarafından uzaktan eğitime yönelik tutumları belirlemek adına "Uzaktan Eğitime Yönelik Tutum Ölçeği” geliştirilmiştir. İki alt boyutlu (Avantaj ve Sinırlılık alt boyutları) ve toplam 21 maddeden oluşan ölçek; 1 (Kesinlikle katılmıyorum)'den 5 (Kesinlikle katılıyorum)'e doğru 5'li likert tipi şeklinde puanlanmıştır. Ölçekte yer alan 1, 2, 3, 4, 5, 6, 7, 8, 9, 10, 16, 18, 20, 21. maddeleri ölçeğin avantaj alt boyutunu oluştururken, 11, 12, 13, 14, 15, 17, 19. maddeleri ise sinırlıl1k alt boyutunu oluşturmaktadır. Ölçeğin orijinal çalışmasında Cronbach Alpha değeri $(\alpha), 835$ bulunmuş, mevcut araştırmada ise avantaj alt boyutunun Cronbach Alpha $(\alpha)$ değeri $(, 804)$ sınırlılık alt boyutunun değeri $(, 825)$ ve son olarak ölçeğin genel toplam değeri $(, 871)$ olarak hesaplanmıştır.

Yarı Yapılandırılmış Görüşme Formu: Nitel veriler toplamak için yarı yapılandırılmış görüşme formu kullanılmıştır. Bu form uzman görüşüne göre ve araştırmada nicel olarak kullanılan ölçek boyutları dikkate alınarak hazırlanmıştır.

Soru 1-) Uzaktan eğitimi faydalı buluyorum çünkü...

Soru 2-) Uzaktan eğitimi faydalı bulmuyorum çünkü...

\section{Verilerin Analizi}

Bilgisayar ortamında hazırlanan veriler araştırmacılar tarafından çevrim içi form haline getirilmiş ve öğrencilerin sorulan sorulara gönüllük esaslı cevap vermeleri istenmiştir. $\mathrm{Bu}$ araştırmada istatistiksel analizler için SPSS paket programı kullanılmıştır. Verilerin normal dağılım gösterip göstermediğini belirlemek amacıyla skewness (çarpıklık) ve kurtosis (basıklık) test sonuçlarına bakılmıştır. Test sonuçlarına göre verilerin $-1,5$ ve $+1,5$ değerler arasında olduğu, normal dağıldığı (Tabachnick ve Fidell, 2013) tespit edilmiş ve parametrik testler kullanılmıştır. İkili grup karşılaştırmaları için bağımsız örneklem t testi, ikiden fazla grup karşılaştırmaları içinse tek yönlü varyans analizi (one-way Anova) testi kullanılmıştır. Anlamlılık düzeyi $(\mathrm{p})<0,05$ olarak kabul edilmiştir.

Araştırmanın nitel boyutunda, spor bilimleri eğitimi alan yükseköğrenim öğrencilerinin açık uçlu sorulara verdikleri yanıtlar içerik analizi yöntemiyle incelenmiştir. İçerik analizi yapılırken verilerin kodlanması, temaların bulunması, verilerin tema-kodlara göre düzenlenmesi ve bulguların yorumlanması adımları sırasıyla takip edilmiştir. Nitel veri seti öğretmenlik eğitimi alan öğrenciler için Ö1, Ö2, Ö3.., antrenörlük eğitimi alan öğrenciler için A1,A2,A3.., spor yöneticiliği eğitimi alanlar içinse Y1, Y2, Y3... şeklinde kodlanmıştır. Araştırmada; iki açık uçlu sorudan alınan cevaplar neticesinde 512 kod elde edilmiştir. 512 kodun 505'sinde görüş birliği, 7 kodda ise görüş ayrılığı yaşanmıştır. Kodlayıcılar arasındaki tutarlılık, verilerin güvenirliğini göstermesinden dolayı (Baltacı, 2017) Miles ve Huberman'ın (1994) aşağıdaki güvenirlik analizi formülü tercih edilmiştir:

Görüş birliği/ (Görüş birliği + Görüş ayrılı̆̆ 1 ) x 100

Formül dikkate alınarak yapılan işlem sonucunda .98 oranında bir güvenirlik saptanmıştır. 
Ünlü, H., Aktaş, Ö. ve Büyüktaş, B. (2021). Spor bilimleri öğrencilerinin uzaktan eğitime yönelik tutum ve görüşlerinin incelenmesi. Spor Bilimleri Araştırmaları Dergisi, 6(2), 294-306.

\section{BULGULAR}

\section{Nicel Verilere İlişkin Bulgular}

Tablo 1. Öğrencilerin cinsiyet değişkenine göre uzaktan eğitime karşı tutum düzeylerinin karşılaştırılması

\begin{tabular}{|c|c|c|c|c|c|}
\hline Alt Boyutlar ve Toplam Tutum & & $\mathbf{n}$ & $\overline{\mathbf{X}} \pm S$ & $\mathbf{t}$ & $\mathbf{p}$ \\
\hline \multirow{2}{*}{ Avantaj } & Kadın & 106 & $2.99 \pm 1.50$ & \multirow{2}{*}{.534} & \multirow{2}{*}{0.68} \\
\hline & Erkek & 150 & $3.02 \pm 1.65$ & & \\
\hline \multirow{2}{*}{ Sinırlılık } & Kadın & 106 & $2.75 \pm 2.21$ & \multirow{2}{*}{.657} & \multirow{2}{*}{0.80} \\
\hline & Erkek & 150 & $2.72 \pm 2.12$ & & \\
\hline \multirow{2}{*}{ Tutum } & Kadın & 106 & $2.91 \pm 1.64$ & \multirow{2}{*}{.862} & \multirow{2}{*}{0.88} \\
\hline & Erkek & 150 & $2.92 \pm 1.72$ & & \\
\hline
\end{tabular}

Tablo 1 incelendiğinde cinsiyet değişkeni açısından mevcut öğrencilerin uzaktan eğitime karşı tutum puanları arasında anlamlı bir fark olup olmadığını tespit etmek amacıyla bağımsız örneklem $t$ testi yapılmıştır. Test sonuçlarına göre cinsiyetin; avantaj $(\mathrm{t}=, 534 ; \mathrm{p}=0,68>.05)$, sinırlılık $(\mathrm{t}=, 657 ; \mathrm{p}=0,80>.05)$ ve toplam tutum puanları üzerinde $(\mathrm{t}=, 862 ; \mathrm{p}=0,88>.05)$ anlamlı kabul edilebilecek bir farklılığa sebep olmadığı görülmüştür.

Tablo 2. Öğrencilerin bölüm değişkenine göre uzaktan eğitime karşı tutum düzeylerinin karşılaştırılması

\begin{tabular}{|c|c|c|c|c|c|}
\hline $\begin{array}{c}\text { Alt Boyutlar ve Toplam } \\
\text { Tutum }\end{array}$ & Bölüm Değişkeni & $\mathbf{n}$ & $\overline{\mathbf{X}} \pm S$ & $\mathbf{F}$ & $\mathbf{p}$ \\
\hline \multirow{3}{*}{ Avantaj } & Beden Eğitimi ve Spor Öğrt. & 99 & $3.09 \pm 1.51$ & \multirow{3}{*}{2.216} & \multirow{3}{*}{0.11} \\
\hline & Antrenörlük Eğitimi & 83 & $2.90 \pm 1.74$ & & \\
\hline & Spor Yöneticiliği & 74 & $3.04 \pm 1.25$ & & \\
\hline \multirow{3}{*}{ Sinırlılık } & Beden Eğitimi ve Spor Öğrt. & 99 & $2.76 \pm 2.06$ & \multirow{3}{*}{2.286} & \multirow{3}{*}{0.10} \\
\hline & Antrenörlük Eğitimi & 83 & $2.57 \pm 2.17$ & & \\
\hline & Spor Yöneticiliği & 74 & $2.86 \pm 2.14$ & & \\
\hline \multirow{3}{*}{ Tutum } & Beden Eğitimi ve Spor Öğrt. & 99 & $2.98 \pm 1.63$ & \multirow{3}{*}{.309} & \multirow{3}{*}{0.53} \\
\hline & Antrenörlük Eğitimi & 83 & $2.79 \pm 1.78$ & & \\
\hline & Spor Yöneticiliği & 74 & $2.98 \pm 1.43$ & & \\
\hline
\end{tabular}

Tablo 2 incelendiğinde bölüm değişkeni açısından mevcut öğrencilerin uzaktan eğitime karş1 tutum puanları arasında anlamlı bir fark olup olmadığını belirlemek adına tek yönlü varyans analizi (one-way Anova) yapılmıştır. Test sonuçlarına göre bölüm değişkeninin; avantaj $(\mathrm{F}=2,216 ; \mathrm{p}=0,11>.05)$, sinırlıl1k $(\mathrm{F}=2,286 ; \mathrm{p}=0,10>.05)$ ve toplam tutum puanları $(\mathrm{F}=2,286$; $\mathrm{p}=0,53>.05)$ üzerinde anlamlı kabul edilebilecek bir farklılığa sebep olmadığı görülmüştür.

\section{Nitel Verilere İlişkin Bulgular}

Tablo 3. Üniversite öğrencilerinin uzaktan eğitimin avantajlı yönlerine ilişkin görüşleri

\begin{tabular}{|c|c|c|c|}
\hline Tema & Alt Tema & Kod & Frekans (f) \\
\hline \multirow{7}{*}{ Avantaj } & Eğitimin sürdürülebilirliği & Risk & 95 \\
\hline & \multirow{3}{*}{ Zaman ve mekân avantaj1 } & Tekrar imkânı & 62 \\
\hline & & Zaman özgürlüğü & 14 \\
\hline & & Uzaktan erişim & 12 \\
\hline & \multirow{3}{*}{ Fursat eşitliği } & Kayit & 56 \\
\hline & & Adalet & 21 \\
\hline & & Eşitlik & 14 \\
\hline
\end{tabular}


Tablo 3 incelendiğinde spor bilimleri alanında öğrenim gören üniversiteli öğrencilerin uzaktan eğitimin avantajlı yönlerine dair görüşleri verilmiştir. Pandemiye rağmen eğitim öğretimin sürdürülebilmesi ve zaman-mekân sınırlarını ortadan kaldırması üzerine fikirlerin yoğunlaştığı görülmüştür. Öğrencilerin görüşlerinin bazıları ise şu şekildedir:

Ö8: 'Virüs hava yoluyla bulaştığından dolayı şu an yüz yüze kapalı sınıf ortamlarında ders işlemek herkes için risklidir.',

A39: 'Sınıfın kalabalık olması ve maskeyle ders işlemenin zor olmasından dolayı sınıfta ders yapmak şu an için aşırı riskli,'

A19: 'Bazen bir dersi o an hoca anlatırken anlayamayabiliyorum. Ders videoları sisteme kayıt edildiğinden dilediğim zaman dinleyip tekrar yapabiliyorum.",

Y71: 'Üniversitem başka şehirde olduğu için maddi olarak ciddi anlamda giderim oluyordu. Fakat online şekilde uzaktan erişimle derslerimi işleyebiliyorum.",

Ö21: ' Dersler kayıt altına alındığından hocalar hiçbir öğrenciye yüz yüze olduğu zamandaki gibi ayrımcılık yapamıyor, herkes eşit."

Ö45: '’Daha önce bazı hocalar dersleri çok az işlerdi. Şimdi kayıt altına alındığı için layığıyla dersler yapiliyor."

Tablo 4. Üniversite öğrencilerinin uzaktan eğitimin dezavantajlı yönlerine ilişkin görüşleri

\begin{tabular}{clll}
\hline Tema & Alt Tema & Kod & Frekans (f) \\
\hline \multirow{4}{*}{ Dezavantajlar } & \multirow{3}{*}{ Avantajları ortadan kaldırması } & Etkisiz iletişim & 51 \\
\cline { 3 - 4 } & & Sosyal ortamların yokluğu & 43 \\
\cline { 3 - 4 } & & Derse katıllma zorunluluğu & 29 \\
\cline { 2 - 4 } & \multirow{2}{*}{ Fizikî şartların yetersizliği } & Etkisiz öğrenme & 15 \\
\cline { 3 - 4 } & & İnternet & 63 \\
\cline { 3 - 4 } & & Sistem & 35 \\
\cline { 3 - 4 } & & Bilgisayar & 20 \\
\hline
\end{tabular}

Tablo 4 incelendiğinde spor bilimleri alanında öğrenim gören üniversiteli öğrencilerin uzaktan eğitimin dezavantajlı yönlerine dair görüşleri verilmiştir. Yüz yüze eğitimin getirmiş olduğu avantajları ortadan kaldırması ile fizikî şartların yetersizliği üzerine fikirlerin yoğunlaştığı görülmüştür. Öğrencilerin görüşlerinin bazıları ise şu şekildedir:

A69: 'Düzenli olarak derse katılma zorunluluğu olmadığından dolayı motivasyonum düşüyor.',

A32: "Antrenörlük bölümü öğrencisiyim ve uygulamalı derslerimi etkili işleyemiyorum."

Ö55: " Karş11ıklı etkili iletişim zayıf ve duygulardan yoksun."

Y41: 'Etkili iletişim yok. 5 duyu organına hitap etmiyor.',

Ö40: "'Okuldaki sosyal ortamlarımızı çok özledim.'”

Y10: "İnternet hakkım az olduğundan dolayı internet sıkıntısı yaşıyorum." 
Ünlü, H., Aktaş, Ö. ve Büyüktaş, B. (2021). Spor bilimleri öğrencilerinin uzaktan eğitime yönelik tutum ve görüşlerinin incelenmesi. Spor Bilimleri Araştırmaları Dergisi, 6(2), 294-306.

Y26: 'Uzaktan eğitim için kullanacağımız sistem çok karışık maalesef ve tam olarak nasıl kullanacağımı bilmiyorum."

Ö12: 'Online eğitim için kullandığım bilgisayarım oldukça eski ve çok yavaş."'

Y74: "İnternet çok yavaş, hocanın görüntüsü ve sesi birbiriyle uyumlu değil.",

\section{TARTIŞMA VE SONUÇ}

COVID-19 pandemisi başta sağlık olmak üzere ticaret, spor, turizm, sanat ve eğitim faaliyetlerini olumsuz etkilemiştir. Bu sebeple alternatif çözüm önerileri bulma konusunda yöneticiler ve bilim insanları arayış içerisine girmiştir. Eğitim faaliyetlerinin devamlılığını sağlamak için uzaktan eğitim yöntemi bir anda hayatlarımıza dahil edilmiş ve araştırmacıların ilgi odağı olmuştur. Bu araştırma spor bilimleri alanında yükseköğrenim gören öğrencilerin mevcut COVID-19 pandemi döneminde uzaktan eğitimle yürütülmekte olan derslere karş1 görüşleri, tutumları hakkında bilgiler sunmuş ve ilgili literatür dikkate alınarak sonuçların kritiği araştırmacılar tarafindan yapılmıştır.

Mevcut araştırmada cinsiyetin, uzaktan eğitimin avantajları ve sınırlılıkları üzerinde anlamlı olarak kabul edilebilecek bir farklılığa sebep olmadığı görülmüştür. Bu dönemde yapılan araştırmalar incelendiğinde mevcut araştırmanın bulgularıyla paralellik gösteren (Düzgün ve Sulak, 2020; Orçanlı ve Bekmezci, 2020; Türküresin, 2020) araştırmalar bulunmaktadır. Kişilik kuramlarından biri olan durum yaklaşımı, kişinin davranışının ve tutumunun büyük ölçüde durum ya da çevre tarafindan belirlendiğini öne sürmektedir (Weinberg ve Gould, 2014). Mevcut pandemiden dolayı kısıtlanan hayatlara bakıldığında öğrenci grupları için farklı çevre durumlarının olmadığı bilinmektedir. Nitekim toplumun büyük çoğunluğu günlük yaşantısını evinde izole bir şekilde geçirmektedir. Farklı durum ve çevre koşullarının olmayışından dolayı farklı düşünce ve algı yapısına bürünemeyeceği düşünülen öğrencilerin anlamlı bir şekilde uzaktan eğitime yönelik tutum düzeylerinin değişmemesi muhtemel görülmektedir. Fakat bazen cinsiyet faktörü; farklı düşünmeyi, farklı algılamayı ve farklı bakış açısına sahip olmayı beraberinde getiren bir faktördür. Alan yazında durum yaklaşımından kısmen ya da tamamen farklı olan (psikodinamik yaklaşım, etkileşimsel yaklaşım, fenomenolojik yaklaşım) kuramlar da bulunmaktadır (Weinberg ve Gould, 2014). Nitekim Aktaş ve diğerleri (2020) tarafindan yapılan bir araştırmada, spor bilimleri öğrencilerinin, pandemi döneminde uzaktan eğitime yönelik tutumların belirlemek amacıyla sordukları beş soruda, cinsiyetin uzaktan eğitime yönelik tutum üzerinde anlamlı bir farklıllğa neden olduğunu tespit etmişlerdir. Çevrim içi işlenen dersleri düzenli olarak takip etme konusunda da yine cinsiyetin anlamlı bir farklılığa sebep olduğu Bingöl (2020a) tarafindan yapılan araştırma sonucunda ortaya çıkarılmıştır. Gürler, Uslu ve Daştan (2020) tarafından yapılan başka bir araştırmada ise yine cinsiyetin, çevrim içi dersleri ve uzaktan eğitimin genel sistemini başarılı bulup bulmama, dersleri düzenli olarak takip edip etmeme, uzaktan eğitimin derse olan ilgiyi artırıp artırmaması konularında da anlamlı bir farklılığa neden olduğu saptanmıştır. Cinsiyetten kaynaklanan farklı bakış açısı ve farklı duygu durumların bu araştırmalarda etkili olduğu söylenebilir.

Bölüm değişkeninin, uzaktan eğitimin avantajları ve sınırlıllkları üzerinde anlamlı bir farklılığa neden olmadığı tespit edilirken antrenörlük eğitimi öğrencilerinin en düşük tutum düzeyine sahip olduğu saptanmıştır. Antrenörlük eğitiminde; antrenman eğitimi verilmekte, 
kamu tarafından desteklenen veya özel olarak kurulan spor örgütlerinin farklı spor dallarına antrenör yetiştirilmektedir. Antrenörlük eğitimi alan kişinin kendi branşında eğitim verecek düzeye gelebilmesi için antrenmanlarını düzenli olarak yapması, kendini geliştirmesi beklenir. Fakat mevcut pandemi sebebiyle uygulanan kisitlamalardan dolayı antrenman yapma firsatı çok az olan ya da firsat bulamayan öğrencilerin tutum puanlarının daha düşük çıktığı düşünülmektedir. Kahraman (2020) tarafından yapılan bir araştırmada uygulama dersinin (temel tasarım dersi) uzaktan eğitim ile başarıya ulaştığı tespit edilmiştir. Fakat her uygulama dersinin içeriği bölümlere göre değişmektedir. Bakıldığında kimya veya biyoloji eğitimi gören öğrencilerin evde deney düzeneği kurması ve araç gereçlerini toparlaması (Kahraman, 2020) ya da spor bilimleri öğrencilerinin ev ortamında tenis, basketbol, yüzme çalışabilmesi neredeyse imkânsızdır. Bu bilgiler ışığında her uygulamalı dersin uzaktan eğitim yöntemiyle yürütülemeyeceği anlaşılmaktadır. Nitekim Kürtüncü ve Kurt (2020) hemşire adaylarının staj ve uygulama derslerini klinik ortamda alamadıkları için stres ve kaygı yaşadıklarını tespit etmişlerdir.

Yüz yüze eğitimin getirdiği avantajları (etkili iletişim, etkili öğrenme, sosyal ortamlar, derse gelme zorunluluğu) ortadan kaldırması ve mevcut fizikî şartların yeterli olmamasından dolayı öğrencilerin uzaktan eğitimi faydalı görmedikleri tespit edilmiştir. Üniversitelerin altyap1 durumları, uzaktan eğitimin yazılımla ilgili boyutu, öğrenci ve öğretmenlerin tecrübeleri, öğrencilerin ekonomik durumları ve internete erişim olanakları gibi durumları değerlendirmeden plansız fakat zorunlu geçişin dezavantajlı durumları beraberinde getirmesinin muhtemel olduğu düşünülmektedir. Nitekim uzaktan eğitimin dezavantajlarını irdeleyen araştırmalara bakıldığında; fizikî şartların yeterli olmaması, yüz yüze eğitimin getirdiği avantajları ortadan kaldırması (etkili iletişim, sosyal ortamlar, derse gelme zorunluluğu, etkili öğrenme), mesleki yetkinlik algısında düşüş (Adnan ve Anwar, 2020; McKenna, 2018; Sarığlan, Altaş ve Şen, 2020; Syauqi, Munadi ve Triyono, 2020) gibi konulara ek olarak uzaktan eğitimin yüz yüze eğitim gibi etkili olamayacağına vurgu yapan yerli ve yabancı (Dolmacı ve Dolmacı, 2020; Sarığlan Altaş ve Şen, 2020; Sutiah ve diğerleri, 2020; Unger ve Meiran, 2020) araştırmalar mevcuttur. Bu bulgular mevcut araştırmanın bulgularıyla paralellik göstermektedir.

Öğrencilerin pandemiden kaynaklı yüz yüze eğitimin taşıdığı riskten, zaman ve mekân avantajı sağlamasından ve eğitimde fursat eşitliği sunmasından dolayı uzaktan eğitimi faydalı buldukları tespit edilmiştir. Alan yazın incelendiğindeyse çevrim içi olarak yapılan eğitim ile yüz yüze yapılan eğitim arasında önemli bir fark bulamayan hatta lisans (Pei ve Wu, 2019) ve ortaokul (Pınar ve Dönel Akgül, 2020) düzeyinde öğrenme deneyimini geliştirebileceğine yönelik bulgular tespit eden araştırmalar bulunmaktadır. Yine uzaktan eğitimin, öğrencilerin kendi istekleri doğrultusunda hızlı ve rahat öğrenmelerine (Indira ve Sakshi, 2020), daha fazla bilgi keşfetmelerine (Harsasi, 2015), öğrenim etkinliklerini tamamlama maliyetini düşürmelerine (Joosten ve Cusatis, 2020) ve bol tekrar yapmalarına (Özgöl, Sarıkaya ve Öztürk, 2017) yardımcı olabileceğini tespit ederek avantajlı yönlerine dikkat çeken araştırmalar da bulunmaktadır. Bu bulgular mevcut araştırmanın bulgularıyla örtüşmektedir.

Sonuç itibariyle spor bilimlerinde yükseköğrenim gören öğrencilerin; cinsiyet ve bölüm değişkenleri açısından uzaktan eğitime karşı tutumlarında anlamlı düzeyde bir farklılık tespit edilmemiştir. Ayrıca erkeklerin uzaktan eğitime karşı tutum puanları kızlara göre daha yüksektir. Öğrenciler, uzaktan eğitimi; pandemiden kaynaklı yüz yüze eğitimin taşıdığı risk, 
zaman-mekân avantajı sunması ve eğitimde fursat eşitliği sağlamasından dolayı avantajlı bulurken; yüz yüze eğitimin getirdiği avantajları ortadan kaldırması (etkili iletişim, sosyal ortamlar, derse gelme zorunluluğu, etkili öğrenme) ve fizikî şartların yeterli olmamasından dolayı dezavantajlı olarak görmüşlerdir.

İnsan hayatını bölgesel ya da küresel olarak olumsuz etkileyen doğal afetler, biyolojik problemler ve savaşlar tarih boyunca hep var olmuştur. Mevcut teknolojik gelişmeler ışığında uzaktan eğitim sisteminin verimliliğini arttırmak özellikle de uygulama dersleri için yeni teknolojik gelişmeler sunmak yukarıda bahsedilen problemlerle karşılaşıldığında eğitim faaliyetlerinin aksamaması adına önem arz etmektedir. Çünkü bu pandemi dönemi uzaktan eğitim sistemi için zorunlu bir deneyim fırsatı sağlayarak eksik ve hatalı yönlerin tespit edilmesine ve bu konuyla ilgili çok sayıda araştırma yapılıp bilgi birikiminin artmasına sebep olmuştur. Spor bilimleri öğrencilerine özellikle uygulama dersleri için zihinsel antrenman yöntemlerinden biri olan imgelemeye başvurarak antrenmanlarını zihinsel olarak yapmaları önerilmektedir. Nitekim imgeleme yöntemi sakatlık sonrası spora dönüş için bile klinik spor psikologları tarafindan kullanılmakta ve sporcunun spor ortamına tekrar adapte olmasını sağlamaktadır. Yine uygulama derslerini sanal gerçeklik (VR) yöntemiyle işletebilecek yazılım ve donanımların geliştirilmesinin uzaktan eğitime katkı sağlayacağı düşünülmektedir.

Çıkar Çatışması: Mevcut makalenin yazarları arasında kişisel veya finansal çıkar çatışması bulunmaktadir.

Araştırmacıların Katkı Oranı Beyanı: Yazar/ların araştırmaya katkı durumları bu bölümde açıklanmalıdır. Araştırma Dizaynı-HÜ, Verilerin Toplanması- ÖA; BB, istatistik analiz- ÖA; BB, Makalenin hazırlanması, HÜ; ÖA.

\section{Etik Kurul İzni ile ilgili Bilgiler}

Kurul Adı: Aksaray Üniversitesi Rektörlüğü İnsan Araştırmaları Etik Kurulu

Tarih: 22.06.2020

Sayı No: $2020 / 06-90$

\section{KAYNAKLAR}

Adnan, M. ve Anwar, K. (2020). Online learning amid the COVID-19 pandemic: students' perspectives. Online Submission, 2(1), 45-51. https://doi.org/10.33902/JPSP. 2020261309

Agasisti, T. ve Soncin, M. (2020). Higher education in troubled times: on the impact of Covid-19 in Italy. Studies in Higher Education, 46(1), 86-95. https://doi.org/10.1080/03075079.2020.1859689

Ağır, F. (2008). Uzaktan eğitime karşı tutum ölçeği geliştirmeye yönelik geçerlilik ve güvenirlik çalışması. Education Sciences, 3(2), 128-139.

Akgün, A. İ. (2020). COVID-19 sürecinde acil durum uzaktan eğitimi yoluyla verilen muhasebe eğitimine yönelik öğrenci görüşleri. Açıköğretim Uygulamaları ve Araştırmaları Dergisi, 6(4), 208-236. 
Ünlü, H., Aktaş, Ö. ve Büyüktaş, B. (2021). Spor bilimleri öğrencilerinin uzaktan eğitime yönelik tutum ve görüşlerinin incelenmesi. Spor Bilimleri Araştırmaları Dergisi, 6(2), 294-306.

Akinbadewa, B., O. \& Sofowora, O., A. (2020). The effectiveness of multimedia instructional learning packages in enhancing secondary school students' attitudes toward Biology. International Journal on Studies in Education, 2(2), 119-133.

Aktaş, Ö., Büyüktaş, B., Gülle, M. ve Yıldız, M. (2020). Covid-19 virüsünden kaynaklanan izolasyon günlerinde spor bilimleri öğrencilerinin uzaktan eğitime karşı tutumları. Sivas Cumhuriyet Üniversitesi Spor Bilimleri Dergisi, 1(1), 1-9.

Alharthi, M. (2020). Students' attitudes toward the use of technology in online courses. International Journal of Technology in Education, 3(1), 14-23. https://doi.org/10.46328/ijte.v3i1.18

Al-Husban, N.A. (2020). Critical thinking skills in asynchronous discussion forums: A case study. International Journal of Technology in Education, 3(2), 82-91. https://doi.org/10.46328/ijte.v3i2.22

Altuntaş, E.Y., Başaran, M., Özeke, B. ve Yılmaz, H. (2020). Covid-19 pandemisi sürecinde üniversite öğrencilerinin yükseköğretim kurumlarının uzaktan eğitime yönelik stratejilerine ve öğrenme deneyimlerine ilişkin algı düzeyleri. Halkla İlişkiler ve Reklam Çalışmaları E-Dergisi, 3(2), 8-23.

Aras, E. ve Karakaya, Y.E. (2020). Spor eğitimi kurumlarında görev yapan akademik personelin uzaktan eğitime yönelik görüşleri: nitel bir çalışma. SPORMETRE Beden Eğitimi ve Spor Bilimleri Dergisi, 18(2), 1-12

Assaf, M. (2020). A new experience of online education under the COVID-19 pandemic for occupational therapy students in Palestine. World Federation of Occupational Therapists Bulletin, 76(2), 103-107. https://doi.org/10.1080/14473828.2020.1825274

Baggaley, J. (2008). Where did distance education go wrong? Distance Education, 29(1), 39-51. https://doi.org/10.1080/01587910802004837

Baltac1, A. (2017). Nitel veri analizinde Miles-Huberman Modeli. Ahi Evran Üniversitesi Sosyal Bilimler Enstitüsü Dergisi, 3(1), 1-14.

Baştürk, S. ve Taştepe, M. (2013). Evren ve Örneklem. Baştürk. S (Ed.), Bilimsel Araştırma Yöntemleri (131158). Ankara: Vize Yayıncilık.

Beard, J. \& Konukman, F. (2020). Teaching online physical education: The art of connection in the digital classroom. Journal of Physical Education, Recreation \& Dance, 91(7), 49-51.

Bingöl, B. (2020a). Peyzaj Mimarlığı Öğrencilerinin COVID-19 sürecinde acil uzaktan öğretim üzerine görüşleri: Burdur Mehmet Akif Ersoy Üniversitesi örneği. Avrupa Bilim ve Teknoloji Dergisi, (20), 890-897. https://doi.org/10.31590/ejosat.805398

Bingöl, Ş. (2020b). Attitudes of the academics in sports sciences towards distance education. African Educational Research Journal, 8(4), 799-805. https://doi.org/10.30918/AERJ.84.20.185

Blankenberger, B. \& Williams, A. M. (2020). COVID and the impact on higher education: The essential role of integrity and accountability. Administrative Theory \& Praxis, 42(3), 1-20. https://doi.org/10.1080/108418062020.1771907

Bruder, I. (1989). Distance learning: What's holding back this boundless delivery system? Electronic Learning, $8(6), 30-35$.

Buluk, B. ve Eşitti, B. (2020). Koronavirüs (COVID-19) sürecinde uzaktan eğitimin turizm lisans öğrencileri tarafindan değerlendirilmesi. Journal of Awareness, 5(3), 285-298. https://doi.org/10.26809/joa.5.021

Byrnes, Y. M., Civantos, A. M., Go, B. C., McWilliams, T. L. \& Rajasekaran, K. (2020). Effect of the COVID19 pandemic on medical student career perceptions: a national survey study. Medical Education Online, 25(1), 1-9. https://doi.org/10.1080/10872981.2020.1798088

Chen, M. (2014). SWOT analysis and strategies to support college physical education through distance education. World Transactions on Engineering and Technology Education, 12(4), 671-674.

Creswell, J. W. (2017). A concise introduction to mixed methods research. Mustafa Sözbilir (Çev.). Ankara, Turkey: Pegem 
Ünlü, H., Aktaş, Ö. ve Büyüktaş, B. (2021). Spor bilimleri öğrencilerinin uzaktan eğitime yönelik tutum ve görüşlerinin incelenmesi. Spor Bilimleri Araştırmaları Dergisi, 6(2), 294-306.

Daum, D. N. (2020). Thinking about hybrid or online learning in physical education? Start here! Editor: Brian Mosier. Journal of Physical Education, Recreation \& Dance, 91(1), 42-44.

de Boer, H. (2020). COVID-19 in Dutch higher education. Studies in Higher Education, 46(1), 1-11. https://doi.org/10.1080/03075079.2020.1859684

Dill, E., Fischer, K., McMurtrie, B. \& Supiano, B. (2020). As coronavirus spreads, the decision to move classes online is the first step. What comes next. The chronicle of higher education. https://www. chronicle. com/article/As-Coronavirus Spreads-the/248200.

Dolmacı, M. ve Dolmacı, A. (2020). Yabancı dil hazırlık sınıfındaki üniversite öğrencilerinin eş zamanlı uzaktan eğitim ile ilgili görüşleri. Milli Eğitim Dergisi, 49(1), 657-684.

Düzgün, S. ve Sulak, S. E. (2020). Öğretmen adaylarının COVID-19 pandemisi sürecinde uzaktan eğitim uygulamalarına iliş̧in görüşleri. Milli Eğitim Dergisi, 49(1), 619-633.

Ekiz, M.A. (2020). Beden eğitimi ve spor yüksekokulu öğrencilerinin karantina dönemindeki uzaktan eğitim ile ilgili görüşleri (Nitel bir araştırma). Spor ve Rekreasyon Araştırmaları Dergisi, 2(Özel Sayı 1), 1-13.

Firat, M., Yurdakul, I. K. ve Ersoy, A. (2014). Bir eğitim teknolojisi araştırmasına dayalı olarak karma yöntem araştırması deneyimi. Eğitimde Nitel Araştırmalar Dergisi, 2(1), 64-85.

Frimming, R. E. \& Bordelon, T. D. (2016). Physical education students' perceptions of the effectiveness of their distance education courses. Physical Educator, 73(2), 340. https://doi.org/10.18666/TPE-2016-V73-I22759

Genç, S. Z., Engin, G. ve Yardım, T. (2020). Pandemi (COVID-19) sürecindeki uzaktan eğitim uygulamalarına ilişkin lisansüstü öğrenci görüşleri. Atatürk Üniversitesi Kazım Karabekir Eğitim Fakültesi Dergisi, (41), 134-158. https://doi.org/10.33418/ataunikkefd.782142

Goad, T., Towner, B., Jones, E. \& Bulger, S. (2019). Instructional tools for online physical education: Using mobile technologies to enhance learning. Journal of Physical Education, Recreation \& Dance, 90(6), 40-47.

Gürler, C., Uslu, T. ve Daştan, İ. (2020). Evaluation of Distance Learning from Student Perspective in Covid-19 Pandemic. Atatürk Üniversitesi Sosyal Bilimler Enstitüsü Dergisi, 24(4), 1895-1904.

Hall, D. \& Knox, J. (2009). Issues in the education of TESOL teachers by distance education. Distance Education, 30(1), 63- 85. https://doi.org/10.1080/01587910902845964

Harrison, T.R. \& Lee, H.S. (2018). iPads in the mathematics classroom: Developing criteria for selecting appropriate learning apps. International Journal of Education in Mathematics, Science and Technology, 6(2), 155-172. https://doi.org/10.18404/ijemst.408939

Harsasi, M. (2015). The use of open educational resources in online learning: A study of students' perception. Turkish Online Journal of Distance Education, 16(3), 74-87. https://doi.org/10.17718/tojde.46469

Indira, D. \& Sakshi, A. (2017). Online learning. International Education \& Research Journal, 3(8), 32-34.

Joosten, T. \& Cusatis, R. (2020). Online learning readiness. American Journal of Distance Education, 34(3), 180-193. https://doi.org/10.1080/08923647.2020.1726167

Kahraman, M. E. (2020). COVID-19 salgınının uygulamalı derslere etkisi ve bu derslerin uzaktan eğitimle yürütülmesi: Temel tasarım dersi örneği. Medeniyet Sanat Dergisi, 6(1), 44-56.

Kaplan, A. M. \& Haenlein, M. (2016). Higher education and the digital revolution: About MOOCs, SPOCs, social media, and the Cookie Monster. Business Horizons, 59, 441-450.

King, F. B., Young, M. F., Drivere-Richmond, K. \& Schrader, P. G. (2001). Defining distance learning and distance education. AACE Journal, 9(1), 1-14.

Kürtüncü, M. ve Kurt, A. (2020). COVID-19 pandemisi döneminde hemşirelik öğrencilerinin uzaktan eğitim konusunda yaşadiklari sorunlar. Avrasya Sosyal ve Ekonomi Araştırmaları Dergisi, 7(5), 66-77. 
Ünlü, H., Aktaş, Ö. ve Büyüktaş, B. (2021). Spor bilimleri öğrencilerinin uzaktan eğitime yönelik tutum ve görüşlerinin incelenmesi. Spor Bilimleri Araştırmaları Dergisi, 6(2), 294-306.

McKenna, K. (2018). The online classroom: A thorough depiction of distance learning spaces. The Journal of Continuing Higher Education, 66(1),13-21. https://doi.org/10.1080/07377363.2018.1415633

Miles, M, B. \& Huberman, A. M. (1994). Qualitative data analysis: An expanded Sourcebook. (2nd ed). Thousand Oaks, CA: Sage.

Mohnsen, B. (2012). Implementing online physical education. Journal of Physical Education, Recreation \& Dance, 83(2), 42-47.

Naidoo, P. \& Cartwright, D. (2020). Where to from here? Contemplating the impact of covid-19 on South African students and student counseling services in higher education. Journal of College Student Psychotherapy, 1-15. https://doi.org/10.1080/87568225.2020.1842279

Omiles, M. E., Dumlao, J. B., Rubio, Q. K. C. \& Ramirez, E. J. D. (2019). Development of the 21st century skills through educational video clips. International Journal on Studies in Education, 1(1), 11-20. https://doi.org/10.46328/ijonse.5

Orçanlı, K., ve Bekmezci, M. (2020). Üniversite öğrencilerinin covid-19 pandemisinde uzaktan eğitim algısının belirlenmesi ve bazı demografik değişkenlerle ilişsisi. Uluslararası İktisadi ve İdari Bilimler Dergisi, 6(2), 88-108. https://doi.org/10.29131/uiibd.836277

Özcan, B., ve Saraç, L. (2020). COVID-19 pandemisi sürecinde öğretmen çevrimiçi uzaktan eğitim rol ve yeterlikleri: Beden eğitimi öğretmenleri örneği. Milli Eğitim Dergisi, 49(1), 459-475.

Özgöl, M., Sarıkaya, İ. ve Öztürk, M. (2017). Örgün eğitimde uzaktan eğitim uygulamalarına ilişkin öğrenci ve öğretim elemanı değerlendirmeleri. Yükseköğretim ve Bilim Dergisi, 7(2), 294-304.

Pambayun, B., Wirjawan, J. V., Wijaya, A., Untung, G. B. \& Pratidhina, E. (2019). Designing mobile learning app to help high school students to learn simple harmonic motion. International Journal on Social and Education Sciences, 1(1), 24-29.

Pei, L. \& Wu, H. (2019). Does online learning work better than offline learning in undergraduate medical education? a systemic review and meta-analysis. Medical Education Online, 24(1), 1-14. https://doi.org/10.1080/10872981.2019.1666538

Pınar, M.A. \& Dönel Akgül., G. (2020). The opinions of secondary school students about giving science courses with distance education during the Covid-19 Pandemic. Journal of Current Research on Social Sciences, 10(2), 461-486.

Pierre, P.S. (1998). Distance learning in physical education teacher education. Quest, 50(4), 344-356.

Sahu, P. (2020). Closure of universities due to Coronavirus Disease 2019 (COVID-19): impact on education and mental health of students and academic staff. Cureus, 12(4), 1-6. https://doi.org/10.7759/cureus.7541

Saltürk, A., ve Güngör, C. (2020). Üniversite öğrencilerinin gözünden covid-19 pandemisinde uzaktan eğitime geçiş deneyimi. Adlyaman Üniversitesi Sosyal Bilimler Enstitüsü Dergisi, (36), 137-174. https://doi.org/10.14520/adyusbd.788716

Sarıoğlan, A. B., Altaş, R. ve Şen., R. (2020). Uzaktan eğitim sürecinde fen bilimleri dersinde deney yapmaya ilişkin öğretmen görüşlerinin araştırılması. Milli Eğitim Dergisi, 49(1), 371-394.

Sawang, S., Newton, C. \& Jamieson, K. (2013). Increasing learners' satisfaction/intention to adopt more elearning. Education+ Training, (55), 83-105.

Sayan, H. (2020). COVID-19 Pandemisi sürecinde öğretim elemanlarının uzaktan eğitime ilişkin görüşlerinin değerlendirilmesi. AJIT-e: Bilişim Teknolojileri Online Dergisi, 11(42), 100-122. https://doi.org/ 10.5824/ajite.2020.03.004.x

Seage, S. J. \& Türegün, M. (2020). The effects of blended learning on stem achievement of elementary school students. International Journal of Research in Education and Science, 6(1), 133-140. https://doi.org/ $10.46328 /$ ijres.v6i1.728 
Ünlü, H., Aktaş, Ö. ve Büyüktaş, B. (2021). Spor bilimleri öğrencilerinin uzaktan eğitime yönelik tutum ve görüşlerinin incelenmesi. Spor Bilimleri Araştırmaları Dergisi, 6(2), 294-306.

Serhan, D. (2019). Web-based homework systems: students' perceptions of course interaction and learning in mathematics. International Journal on Social and Education Sciences, 1(2), 57-62. https://doi.org/10.46328/ijonses. 18

Suleri, J. (2020). Learners' experience and expectations during and post COVID-19 in higher education. Research in Hospitality Management, 10(2), 91-96. https://doi.org/10.1080/22243534.2020.1869463

Sutiah, S., Slamet, S., Shafqat, A. \& Supriyono, S. (2020). Implementation of distance learning during the covid-19 pandemic in faculty of education and teacher training. Cypriot Journal of Educational Science, 15(1), 1204-1214. https://doi.org/10.18844/cjes.v15i5.5151

Syauqi, K., Munadi, S. \& Triyono, M. B. (2020). Students' perceptions toward vocational education on online learning during the COVID-19 pandemic. International Journal of Evaluation and Research in Education, 9(4), 881-886. https://doi.org/10.11591/ijere.v9i4.20766

Şen, Ö. ve Kızılcalığlu, G. (2020). Covid-19 pandemi sürecinde üniversite öğrencilerinin ve akademisyenlerin uzaktan eğitime yönelik görüşlerinin belirlenmesi. International Journal of $3 D$ Printing Technologies and Digital Industry, 4(3), 239-252. https://doi.org/10.46519/ij3dptdi.830913

Tabachnick, B.G. \& Fidell, L.S. (2013). Using Multivariate Statistics (sixth ed.). Boston: Pearson.

Yakovleva, T.A. \& Koriakina, A. A. (2020). Influence of the covid-19 coronavirus distribution on the organization of higher education in Russia. Universal Journal of Educational Research, 8(12), 67456750. https://doi.org/10.13189/ujer.2020.081239.

Tiwari, P., Séraphin, H. \& Chowdhary, N. R. (2020). Impacts of COVID-19 on tourism education: Analysis and perspectives. Journal of Teaching in Travel \& Tourism, 1-26. https://doi.org/10.1080/15313220.2020.1850392

Türküresin, H. E. (2020). COVİD-19 Pandemi döneminde yürütülen uzaktan eğitim uygulamalarının öğretmen adaylarının görüşleri bağlamında incelenmesi. Milli Ĕ̆itim Dergisi, 49(1), 597-618.

UNESCO. (2020, Mart 25). COVID-19 Educational disruption and response. https://en.unesco.org/themes/education-emergencies/coronavirus-school-closures

Unger, S. \& Meiran, W. (2020). Student attitudes towards online education during the COVID-19 viral outbreak of 2020: Distance learning in a time of social distance. International Journal of Technology in Education and Science, 4(4), 256-266. https://doi.org/10.46328/ijtes.v4i4.107

Weinberg, R. S. \& Gould, D. (2014). Foundations of sport and exercise psychology. Champaign. IL: Human Kinetics.

Yakar, L. Y. ve Yakar, Z. Y. (2021). Eğitim fakültesi öğrencilerinin uzaktan eğitime karşı tutumlarının ve eöğrenmeye hazır bulunuşluklarının incelenmesi. Mersin Üniversitesi Eğitim Fakültesi Dergisi, 17(1), 121.

Yu, J. \& Jee, Y. (2021). Analysis of online classes in physical education during the COVID-19 Pandemic. Education Sciences, 11(1), 2-14.

Bu eser Creative Commons Atıf-Gayri Ticari 4.0 Uluslararası Lisansı ile lisanslanmıştır. 